\title{
Cultura indígena e tecnologias digitais da informação e comunicação: uma narrativa sobre formação e empoderamento
}

\author{
Alexsandro Cosmo de Mesquita (PUC/SP) \\ Lucila Pesce (UNIFESP) \\ Ana Maria Di Grado Hessel (PUC/SP)
}

\section{Resumo}

$\mathrm{O}$ artigo narra uma pesquisa sobre os indígenas e o uso de tecnologias digitais. O objetivo da investigação é compreender em que medida os aspectos percebidos na construção da identidade das comunidades indígenas, durante uma experiência de formação, podem auxiliar na compreensão do papel das tecnologias para essas comunidades. O método utilizado foi a pesquisa-ação, mediante o qual o pesquisador de campo situou-se como um praticante social. A observação e o registro da experiência, em um diário de bordo, foram os instrumentos de produção de dados. Os resultados revelam que o uso das tecnologias pelas comunidades indígenas não se reduz ao entretenimento, mas se situa como empoderamento e importante instância em prol da afirmação da identidade desses sujeitos sociais.

Palavras-chave: Cultura Indígena. Tecnologias Digitais da Informação e Comunicação. Narrativa. Formação. Empoderamento.

\section{Indigenous culture and digital information and communication technologies: a narrative on training and empowerment}

\section{Abstract}

The article tells a research about the use of digital technologies by indigenous peoples. The objective of the research is to understand how the perceived aspects in the construction of the identity of the indigenous 
communities, during a training experience, can help in understanding the role of the technologies for these communities. The method used was the action research, where the researcher participated as a social practitioner. The observation and recording of experience, in a logbook, were the instruments of data production. The results show that the use of technologies by indigenous communities is not limited to entertainment, but it is seen as an empowerment and an important instance for the affirmation of the identity of these social subjects.

Keywords: Indigenous Culture. Digital Information and Communication Technologies. Narrative. Formation. Empowerment.

\section{Cultura indígena y tecnologías digitales de la información y comunicación: una narrativa sobre formación y empoderamiento}

\section{Resumen}

El artículo narra una investigación sobre los indígenas y el uso de tecnologías digitales. El objetivo de la investigación es comprender en qué medida los aspectos percibidos en la construcción de la identidad de las comunidades indígenas, durante una experiencia de formación, pueden auxiliar en la comprensión del papel de las tecnologías para esas comunidades. El método utilizado fue la investigación-acción, mediante el cual el investigador de campo se situó como un practicante social. La observación y el registro de la experiencia, en un diario de campo, fueron los instrumentos de producción de datos. Los resultados revelan que el uso de las tecnologías por las comunidades indígenas no se reduce al entretenimiento, sino que se sitúa como empoderamiento e importante instancia en favor de la afirmación de la identidad de esos sujetos sociales. Palabras clave: Cultura Indígena. Tecnologías Digitales de la Información y la Comunicación. Narrativa. Entrenamiento. Empoderamiento.

\section{Introdução}

Este artigo aborda o tema indígenas e tecnologias e apresenta uma pesquisa que narra uma experiência formativa de comunidades indígenas que se desenvolveu com o objetivo de criar planos de trabalho, os quais abarcam a definição de ações que visam a contribuir para o resgate e a manutenção de sua identidade cultural. Seu desenvolvimento se deu diante do cenário crescente 
da utilização do ciberespaço para propagar e discutir questões da vida social relacionadas a política, cultura, educação, meio ambiente, entre outros.

A proposta formativa envolveu oito comunidades indígenas do Nordeste do Brasil, as quais fazem parte do projeto "Mensagens da Terra", gerenciado pela organização não governamental ONG Thydêwá. Por meio de um convênio junto ao Ministério da Cultura, a ONG teve por objetivo facilitar o acesso dessas comunidades ao ciberespaço, utilizando os Pontos de Cultura Indígena (PCI). Os PCI são espaços similares a um telecentro, nos quais os indígenas têm disponível um computador com acesso a internet, dentro de sua própria comunidade. O fato é que o Ministério da Cultura procura estimular as comunidades indígenas a utilizarem a tecnologia para a preservação e o fortalecimento da sua identidade cultural. As etnias presentes nas comunidades participantes, durante o processo de colonização do Brasil, sofreram um processo intenso de perda de sua cultura e por isso já não falam seu dialeto originário e nem praticam muitos dos costumes culturais dos antepassados, diferentemente de outros povos que vivem na região central do país.

No decorrer das oficinas formativas, foi possível observar os aspectos que revelam o desejo das comunidades indígenas de preservar a sua cultura. A experiência mostrou o movimento de empoderamento (BAQUERO, 2012) que as comunidades participantes vivenciaram.

Para realizar a investigação, o pesquisador, um dos autores deste texto e participante das oficinas formativas, optou por utilizar o método de pesquisa-ação, o qual é aconselhável no estudo de ambientes onde haja interação social que se caracterize por um problema, "no qual estão envolvidos pessoas, tarefas e procedimentos" (ENGEL, 2000, p. 181).

A análise interpretativa dos dados revelou que um dos aspectos mais relevantes a serem valorizados é a apropriação do ciberespaço pelas comunidades indígenas como instrumento de for- 
talecimento de suas culturas. De fato, o que vem ocorrendo nas comunidades indígenas é um movimento de reafirmação e valorização da cultura (ALVES, DINIZ, OLIVEIRA, 2014).

\section{Referencial teórico}

O processo de resgate e valorização da cultura indígena vem ocorrendo por meio da criação e publicação de livros escritos e ilustrados pelos próprios indígenas. Estas iniciativas motivaram o nascimento do portal Web Índios Online ${ }^{1}$, além da criação de algumas ciberocas ou Pontos de Cultura Indígena (MESQUITA, 2016). Segundo depoimento apresentado por Gerlic (2011), criador do portal em 2004, o portal é um canal de diálogo intercultural, de encontro e de troca, bem como de promoção de estudos sobre a cultura indígena.

O portal traz informações variadas, desde o relato de momentos comemorativos a narrativa de conflitos, como se os indígenas fossem jornalistas independentes. Apesar de o portal possuir características semelhantes ao do jornalismo independente, Tavares (2013) optou por chamar a elaboração e a divulgação de informações feita pelos indígenas dentro do ciberespaço, de "ciber- informações nativas", visando estabelecer uma separação entre o jornalismo e as novas formas de comunicação produzidas pelos indígenas na internet.

Em uma análise preliminar, os indivíduos indígenas buscam noticiar sua realidade, porém, a partir de uma análise mais aprofundada, percebe-se que o importante não é apenas passar informação, mas também trazer um novo olhar para as mesmas. Pelo olhar que parte da perspectiva de dentro para fora, e não de fora para dentro, o objeto que antes era observado e descrito desde a perspectiva do observador, passa a ser auto observado e descrito. Na perspectiva de Freire e Shor (1986) pode-se dizer que as comunidades indígenas tomam posse do real, pelo olhar crítico que desenvolvem sobre a sua realidade.

${ }^{1}$ http://www.indiosonline.net 
Essa abordagem crítica, intensamente relacionada com o empoderamento é explicada por Baquero (2012, p. 181): “o empoderamento, como processo e resultado, pode ser concebido como emergindo de um processo de ação social no qual os indivíduos tomam posse de suas próprias vidas pela interação com outros indivíduos, gerando pensamento crítico em relação à realidade". Essa atitude favorece a valorização dos sujeitos e fortalece a capacidade pessoal e social de transformar as relações de poder.

O texto de Pesce e Bruno (2015) traz uma reflexão sobre o conceito de empoderamento freireano e esclarece que este é concebido em um contexto de transformação cultural dos grupos sociais. Para as autoras (PESCE; BRUNO, 2015, p. 356) "é imperioso trabalhar a inclusão digital como pertencente ao campo maior da inclusão social, em um movimento capaz de promover a emancipação dos sujeitos sociais envolvidos". No caso das comunidades indígenas, a inclusão social significa que os sujeitos podem se situar coletivamente como leitores e construtores de suas circunstâncias históricas e identidade indígena.

Pereira (2017) tece críticas à caracterização estereotipada que historicamente tem sido feita da cultura indígena. Explica que o uso das mídias digitais, pelos povos indígenas, por meio da apropriação das tecnologias digitais, da interação e da produção de conteúdos em rede, emana da dinâmica cultural indígena, que abarca relações interétnicas (na expressão da autora) e interculturais. Nessa linha de pensamento, a autora acentua alguns movimentos evidenciados em suas pesquisas, como as experiências net-ativistas de resistência, mediante formas de gestão e monitoramento digital dos territórios que lhes foram demarcados e a digitalização das suas territorialidades, dos ecossistemas e de suas culturas.

Além disso, Pereira (2017, p. 179) assevera que o uso das tecnologias digitais, pelos povos indígenas, assenta-se na premissa de que estas novas estratégias comunicativas podem auxiliar a pressionar pela “[...] resolução de problemas históricos como o da garantia do direito à terra e à defesa dos territórios demarcados". 


\section{A experiência formativa das comunidades indígenas}

O processo formativo das comunidades indígenas teve início com a seleção da ONG Thydêwá, pela Secretaria da Identidade e da Diversidade Cultural do Ministério da Cultura, para implantar uma proposta, de acompanhamento e gerenciamento de oito Pontos de Cultura Indígena, em comunidades do Nordeste do Brasil, durante o período de três anos.

Na proposta, a ONG Thydêwá comprometeu-se a cumprir algumas metas, com o intuito de proporcionar o fortalecimento das comunidades indígenas, para que essas apurem a visão crítica e o preparo para projetar seu futuro, com protagonismo, liberdade e autonomia, dignificando a vida dos indígenas e assegurando a sustentabilidade de suas culturas. Em outras palavras, comprometeram-se com o empoderamento dessas comunidades.

Nesta pesquisa relatamos as ações formativas referentes a uma das metas: construir um Plano de Trabalho para o Ponto de Cultura Indígena (PCI) de uma comunidade. A finalidade desse plano é contribuir com a construção e o desenvolvimento da autonomia das comunidades indígenas e auxiliá-las a criar, definir e gerenciar, conforme suas necessidades, as atividades a serem realizadas nos seus PCI.

Para realizar essa meta, foi necessário encontrar um método que auxiliasse os indígenas a cumpri-la de forma coletiva e participativa. Para tanto, a ONG Thydêwá adotou o método Dragon Dreaming $^{2}$, desenvolvido pelo antropólogo John Croft, o qual pode ser considerado um recurso ou estratégia útil para criar de forma lúdica projetos colaborativos sustentáveis. A principal característica da ferramenta é proporcionar uma abordagem estratégica e consensual.

\footnotetext{
2 O recurso Dragon Dreaming é explicado no site: http://www.dragondreaming.org
} 
Em agosto de 2014, a ONG Thydêwá reuniu representantes das comunidades indígenas, para formar uma equipe que seria capacitada, durante cinco dias, no uso do método Dragon Dreaming, com o fim de trabalhar com as oito comunidades participantes do projeto "Mensagens da Terra".

Os projetos criados com a ferramenta Dragon Dreaming seguem um ciclo que é baseado no ciclo de vida, dos elementos da natureza, perfazendo os quatro momentos das estações do ano ou as quatro do dia - nascer do sol, meio dia, pôr do sol e noite. Com base no ciclo de vida, são quatro as fases de um projeto: sonhar, planejar, realizar e celebrar.

O primeiro dia do curso teve início com uma reflexão sobre a humildade para aprender e ensinar. Em seguida foi realizado um toré, ou ritual indígena, e todos se sentaram em círculo. Depois dessa breve reflexão foi colocada no centro do círculo uma vela, representando uma fogueira. A vela foi acesa por alguém que deveria desejar algo bom para o coletivo, enviando energia positiva a todos. Nesse momento, todos se apresentaram e contaram seus sonhos e desejos para os próximos cinco dias de formação. Enquanto os participantes falavam, os sonhos de cada um foram registrados. Em seguida, todos colocaram junto à fogueira um objeto pessoal que os ajudasse a lembrar daquele dia. Uma mandala foi formada.

Na primeira fase da estratégia Dragon Dreaming - sonhar todo projeto nasce a partir dos sonhos de cada indivíduo. Mas, para que um sonho coletivo possa nascer e ser materializado como um projeto do grupo, os sonhos dos indivíduos devem morrer. Nessa fase, todos os participantes, arrumados em dupla, contaram sobre suas experiências com projetos que deram certo e com projetos que não alcançaram sucesso.

Em seguida, todos foram convidados a construir um sonho coletivo, utilizando-se do recurso chamado de círculo dos sonhos. Para isso, os participantes foram divididos em quatro grupos de cinco pessoas. Pensando nos Planos de Trabalho, foi solicitado a 
eles que fizessem uma projeção sobre o que gostariam de ver realizado em um tempo futuro. Os desejos foram registrados em cartolina e passaram a ser chamados de necessidades do projeto. Um membro do grupo realizou a leitura de todas essas necessidades de uma forma especial, tirando os verbos do futuro e colocando-os no passado, como se os três anos já tivessem se passado e os frutos já tivessem sido colhidos.

Alguns dos desejos apresentados foram: ter computadores com acesso a internet; possibilidade de valorizar e divulgar a cultura indígena com o uso desses computadores; utilizar o espaço do Ponto de Cultura Indígena (PCI) para oficinas e realização de rituais como o toré: um ritual indígena apreciado por esta cultura.

No segundo dia foi dado início ao planejamento. O primeiro passo foi definir os objetivos específicos. Todos os participantes escreveram em etiquetas uma ação essencial, para que a totalidade do projeto fosse realizada. Levando em consideração a semelhança das ações, as mesmas foram organizadas em oito colunas e inseridas em um quadro de avisos. As ações deram origem a oito objetivos específicos, os quais foram organizados pelo critério de prioridade.

O próximo passo foi a definição das tarefas para a concretização de cada objetivo, considerando-se curtos períodos de tempo. Essas tarefas foram registradas em ordem de realização em um quadro no formato de diagrama, de tal forma que cada participante pôde se posicionar com relação a cada uma delas, comprometendo-se a cumprir a tarefa ou a contribuir para a sua execução. Algumas das ações que surgiram foram: realizar a limpeza do espaço físico; colher material para a oficina de artesanato; realizar oficinas de informática; produzir matérias para publicar no portal "Índios Online".

No terceiro dia da oficina foi construída a missão do projeto, por meio de uma estratégia chamada frase guarda-chuva. Os participantes do grupo iniciaram com a leitura do círculo dos sonhos, imaginando que todos os itens desejados ou sonhados já tenham sido realizados. Em seguida, todos contribuíram com a criação de uma frase representativa desses sonhos realizados, os quais estão intima- 
mente relacionados com a missão do projeto. A dinâmica iniciou-se com a escolha de uma frase, por um dos participantes. Todos os outros, cada qual por sua vez, foram contribuindo com complementos ou alterações na frase anterior. No final, todos os participantes acrescentaram, retiraram ou trocaram alguma palavra da frase, porém todos colaboraram para a construção da missão do projeto. Ao final, a missão estava pronta e possuía as características de todos.

Antes de terminar os trabalhos do dia, a definição do orçamento das tarefas do projeto foi implantada de forma alegre e ritmada. Ao som de palmas do grupo, os participantes opinavam sobre o custo e o tempo de cada tarefa.

No quarto dia, apos o toré, o curso começou com uma conversa sobre o sonho do PCI. Foram listados os pontos positivos e negativos. Foi criada uma expectativa positiva para os itens mais valorizados. Os possíveis fracassos foram relacionados e foram levantadas as soluções para essas situações, mobilizando a inteligência coletiva.

O quinto e último dia da oficina, como em todos os anteriores, foi iniciado com o toré. Cada participante foi solicitado a expressar, em forma de desenho, seus temores sobre um possível fracasso do projeto e as providências para superar as dificuldades. A seguir foi realizada uma roda de conversa, para refletir sobre a oficina e os produtos gerados durante a formação. O grupo aprendeu que, ao terminar uma tarefa, por mais simples que essa seja, deve-se celebrar, pois o reconhecimento dos feitos e sua comemoração motiva a renovação.

Nos três meses seguintes desta oficina, o pesquisador desta investigação esteve envolvido na formação das oito comunidades indígenas, que fazem parte do projeto "Mensagens da Terra". Em casa, uma delas desenvolveu o método Dragon Dreaming para a definição dos respectivos Planos de Trabalho. Cada comunidade definiu o seu plano, contendo a missão, os objetivos específicos, as tarefas a serem realizadas e o cronograma das atividades do PCI. Também foram criados o orçamento e o calendário de execução 
das tarefas, os custos de manutenção, recursos humanos disponíveis e aqueles ainda necessários à viabilização do projeto. Tratou-se também de parcerias, gestão, prestação de contas, relatórios, captação de recursos e empreendedorismo.

\section{Procedimentos metodológicos}

Para compreender o papel das tecnologias digitais da informação e comunicação (TDIC) na construção e preservação da identidade indígena, a pesquisa focalizou uma experiência de formação, promovida pela ONG Thydêwá para os representantes de oito comunidades participantes do projeto "Mensagem da Terra". A formação teve como objetivo capacitar os participantes a construir um Plano de Trabalho para o seu Ponto de Cultura Indígena. A dinâmica utilizada para a realização das oficinas de formação foi a metodologia Dragon Dreaming, uma estratégia lúdica para criar projetos coletivos e colaborativos.

O método aplicado nesta investigação é a pesquisa-ação. Justifica-se pelo fato de o pesquisador, um dos autores deste texto e indígena da etnia Potiguara, estar envolvido na pesquisa, como participante em formação e como formador. Segundo Barbier (2007), na pesquisa-ação o pesquisador é um participante engajado que aprende durante a pesquisa e os participantes são os sujeitos de uma comunidade que se envolvem para compreender uma situação ou problema. Segundo Tripp (2005, p.5), a "pesquisa-ação é uma forma de investigação-ação que utiliza técnicas de pesquisa consagradas para informar a ação que se decide tomar para melhorar a prática".

Barbier (2007, p. 60) explica que a pesquisa-ação emancipatória pressupõe que os sujeitos envolvidos "compreendam a pesquisa mesma como uma atividade social e política, portanto ideológica". No caso desta pesquisa, os fatores em questão são a preservação da cultura, o empoderamento desta etnia e a contribuição das TDIC para alcançar este intento.

O pesquisador de campo atuou como um praticante social, realizando ações de formação junto às comunidades indígenas. 
Construiu os dados da pesquisa, por meio da observação, de registros fotográficos e do registro da experiência vivenciada em um diário de bordo ou diário de itinerância. Barbier (2007, p.138) explica que o diário de itinerância "é um emaranhado de referências múltiplas a acontecimentos, reflexões, comentários científicos ou filosóficos, devaneios e sonhos, desejos, poemas, leituras, palavras ouvidas, reações afetivas". A narrativa da vivência formativa, bem como os registros fotográficos podem ser encontrados em Mesquita (2016).

Visando refletir sobre a problemática da pesquisa-ação, os dados foram organizados em categorias e interpretados pelo pesquisador. Nesta tarefa interpretativa é importante destacar a imbricação das personagens assumidas pelo pesquisador. Em outras palavras, há que se considerar, além de seu papel de pesquisador, o seu papel de formador das oficinas e de sujeito social de origem indígena. Esse olhar hermenêutico e polivalente permitiu um aprofundamento na essência da questão, por meio do tratamento dos significados, além de uma teorização local, sem a pretensão de propor modelos ou de generalizar.

\section{Olhar interpretativo do pesquisador/ formador}

Durante a realização das oficinas o pesquisador desta pesquisa-ação aprendeu os princípios da construção de projetos colaborativos, tais como saber ouvir e falar no momento certo, fazer parte do sonho e projeto do próximo. Durante a formação das comunidades indígenas, foi necessário estar aberto a novas formas de aprendizagem. A experiência ajudou-o a desconstruir seus conceitos administrativos clássicos de criação de projetos que seguem uma linha hierárquica, na qual um pequeno grupo planeja e a massa deve segui-lo, para adotar um novo conceito, no qual é possível que todos os envolvidos participem da construção do projeto e se sintam parte dele, trazendo para si a responsabilidade, de forma prazerosa, de buscar concretizar o projeto, pois esse participante também é protagonista desta construção. Na verdade, o pesquisador e formador vivenciou os princípios da pedagogia da 
autonomia de Freire (1997), na qual o sujeito constitui-se como sujeito autônomo, na medida em que protagoniza o seu percurso histórico centrado nas experiências estimuladoras de decisão, responsabilidade e liberdade.

Ao refletir sobre todas as suas vivências, o pesquisador/ formador organizou uma análise interpretativa segundo alguns critérios: aprendizagem lúdica, uso das TDIC pelos indígenas, acesso às TDIC e preservação da identidade indígena.

No tocante ao critério aprendizagem lúdica, percebeu-se que o uso do Dragon Dreaming facilitou a criação dos Planos de Trabalho, pelos próprios indígenas, de forma lúdica. Todos os passos do processo - sonhar, planejar, realizar e celebrar - foram vivenciados prazerosamente, favorecendo a integração, a troca de ideias e o fortalecimento da identidade indígena.

A aprendizagem lúdica sempre esteve presente no universo indígena e este aspecto foi uma constante nas atividades da formação. As letras de canções presentes em seus rituais, em sua grande maioria, narram fatos de sua cultura. A junção da oralidade e dos movimentos corporais, instrumentos utilizados por milênios, sempre ajudaram a preservar, por meio da repetição das histórias antigas, os costumes indígenas.

O toré, ritual praticado pelos indígenas nos momentos de preparação de uma batalha e utilizado em celebrações, foi utilizado no início e no término das atividades diárias. O ritual, por fazer parte da cultura indígena, foi importante para manter a coesão do grupo, bem como para estimular a produção coletiva. Percebe-se que os aspectos culturais das comunidades foram valorizados durante a formação, não só para ambientar os participantes, mas também em sinal de respeito aos seus anseios de manutenção e valorização da cultura. Em seu discurso, Gerlic (2011) defende a preservação e a valorização dos aspectos culturais nas comunidades indígenas.

Aspectos do uso da TDIC pelos indígenas foi uma outra categoria analisada. No início da formação, o cacique solicitou que fosse gravado um vídeo para ser postado no portal Web Índios 
Online, com o propósito de denunciar e mostrar à parcela da sociedade, que acessa ao portal, aspectos da vida indígena que precisam ser uma meta: expressou que seu desejo era ver os mais jovens e as crianças da comunidade fazendo uso do Ponto de Cultura Indígena, em especial da internet, para postar no ciberespaço as notícias da comunidade.

Percebe-se nesse contexto o indígena como produtor das informações referentes a ele mesmo e a apropriação de diferentes meios na construção deste produto informacional, que parte do olhar do próprio membro da comunidade. A utilização da escrita e do vídeo, utilizada outrora por pesquisadores, agora é utilizada pelo indígena, dando-lhes oportunidade de se auto descrever, permitindo o nascimento de uma nova perspectiva. Lazaneo (2012, p. 52) conta: "Antigamente nossa cultura foi registrada pelo trabalho de não índios. Eles fizeram muitas filmagens, fotografias e livros a partir de sua visão e interpretação e foi com essa visão que fizeram divulgação de nossas práticas culturais". A divulgação de imagens obtidas a partir do olhar de fora para dentro e sem um diálogo respeitoso com o objeto analisado, pode ferir e macular a crença indígena e outros valores culturais. $\mathrm{O}$ autor explica que isso se modificou, pois atualmente são os indígenas que tratam de contar sobre si.

Com base nas informações coletadas durante a formação, bem como a partir das experiências apresentadas sobre a utilização das TDIC por comunidades indígenas, percebe-se a importância de ampliar, além do olhar externo, o olhar de dentro, ou seja, o olhar do sujeito que é analisado. Pode-se dizer que o portal Web Índios Online, criado por Gerlic (2012) é utilizado pelos indígenas como uma ferramenta de afirmação de identidade, existência e comunicação intercultural. Percebe-se, também, que os indígenas anseiam por preservar seus símbolos, principalmente os utilizados por seus ancestrais. Além disso, em concordância com Pereira (2017), há um desejo de usar esse espaço comunicacional para divulgar a todos, no ciberespaço, os problemas enfrentados pelos povos indígenas. Esta. 
Com relação à categoria acesso às TDIC, as comunidades expressaram suas expectativas com relação a melhorias na comunicação, por meio do uso dos computadores nos Pontos de Cultura Indígena e nas escolas de sua região. Relataram que a chegada da escola na comunidade, a qual hoje já possui um currículo criado por professores indígenas, pode ser comparada à chegada e à criação de um polo de acesso à informação. O "Programa Um Computador por Aluno" (UCA ${ }^{3}$ ) também chegou em algumas comunidades indígenas, mas ainda há uma resistência na utilização desses recursos de produção e acesso às mídias digitais. A falta de profissionais da área de informática, ou áreas similares, a falta de interesse, a resistência ao novo e o analfabetismo digital são fatores que contribuem para o desinteresse na utilização desses dispositivos digitais, por parte dos docentes. E quando os jovens estudantes indígenas trazem seus celulares com acesso à internet ou mesmo os tablet que ganharam através do Programa UCA para a escola, com a finalidade acessar o ciberespaço, são impedidos pela direção que alega o uso indevido do ambiente virtual.

Durante toda a formação, aspectos da preservação da identidade indígena, mais uma categoria definida, pôde ser observada. A todo momento algumas palavras se repetem no discurso das comunidades, como: fortalecimento, cultura, resgate, preservação. Se analisadas nos contextos nos quais emergiram, demonstram a preocupação desses grupos em manter vivo o pouco da identidade étnica que lhes restara. Na explicação de Baquero (2012),

O projeto UCA - Um Computador por Aluno foi implantado com o objetivo de intensificar a integração das tecnologias digitais da informação e da comunicação às práticas de aprendizagem, no seio das escolas, por meio da distribuição de computadores portáteis aos alunos da rede pública de ensino. Para mais detalhes ver: http://www.fnde.gov.br/programas/ proinfo/eixos-de-atuacao/programa-um-computador-por- aluno-prouca comunidade, através dos cantos ou das rodas de conversas, junto à fogueira, graças ao acesso às tecnologias digitais de comunicação e informação, já se encontram registradas em livros, blogs, sites e aplicativos, enfim, em diferentes linguagens hipermidiáticas. 
estes são indícios de um processo de ação social ou empoderamento, no qual os sujeitos procuram gerir suas vidas com autonomia e pensamento crítico em relação à realidade.

No tocante às metas e objetivos pensados na formação das comunidades, encontramos vestígios da preocupação dos indígenas em usar as TDIC para a preservação da sua cultura: construir uma comunidade mais consciente, utilizar o espaço do PCI para aprender, ensinar, trocar experiência com outras culturas, realizar ações sustentáveis, divulgar nossas ações no portal Web Índios Oline, fazer oficinas de diversos temas, fazer roda de conversa com os anciões para preservar a memória etc.

Alguns aspectos presentes na identidade dos povos indígenas são seus rituais, secretos ou não, sua dança, seu canto, a fabricação de artesanatos, adornos, sua relação com a terra e os animais, suas histórias, símbolos e ícones que os mantêm em

\section{Considerações finais}

As TDIC têm sido utilizadas pelos povos indígenas para se organizarem e realizarem reivindicações em defesa de sua identidade cultural, em um verdadeiro processo de empoderamento. As oficinas nas comunidades indígenas mostraram que essa é uma tendência desejada pelos indígenas. As tecnologias que foram utilizadas como forma de inserir o indígena na sociedade sob a perspectiva do homem branco, ganham novas configurações, dando vozes a esses povos, além de serem utilizadas como instrumento de luta contra o esquecimento e a negação de suas origens, na forma de preservação dos seus costumes; ferramenta para resistir, reivindicar, resgatar, manter aspectos culturais, conquistar e manter direitos, ter acesso ao conhecimento.

Dentro de um panorama geral conclui-se que o uso das linguagens hipermidiáticas do ciberespaço, pelos indígenas, vem contribuindo para: a reafirmação do "eu identitário", o reconhecimento "da identidade étnica"; a troca de conhecimento entre culturas, indígena ou não, nacional ou internacional, além de contribuir para 
a criação de uma rede de comunicação multiétnica. Há um movimento de resgate, manutenção e preservação cultural, no qual os indígenas que tiveram que negar suas raízes e perderam muito dos seus costumes ancestrais, vêm buscando, com auxílio das tecnologias digitais da informação e comunicação, os símbolos e significados que restaram para entrar em contato com o seu eu autóctone e manter vivos aspectos de sua identidade cultural.

\section{Referências}

ALVES Mario, DINIZ Eduardo, OLIVEIRA Lya. Tecnologia da Informação e Comunicação como Instrumento Político: Um estudo sobre acesso à internet dos povos Indígena. Fundação Getulio Vargas, 2014. Disponível em: https:/ / aisel. aisnet.org/cgi/viewcontent.cgi?article $=1671 \&$ context $=$ amcis2014. Acesso em 13 de setembro de 2017.

BAQUERO, Rute. Empoderamento: instrumento de emancipação social? Uma discussão conceitual. Revista Debates (UFRGS), Porto Alegre, v. 6, n. 1, p. 173187, jan.- abr. 2012. Disponível em: http://seer.ufrgs.br/debates/article/viewFile/26722/17099. Acesso em 09 março de 2018.

BARBIER, René. A pesquisa-ação. Brasília: Líder Livro Editora, 2007. ENGEL, Irineu Guido. Pesquisa-ação. Educa, Curitiba, n. 16, p. 181-191. 2000. Editora da UFPR. Disponível em: http://www.educaremrevista.ufpr.br/arquivos_16/irineu_engel.pdf. Acesso em 06 de maio de 2017.

FREIRE, Paulo. Pedagogia da Autonomia: saberes necessários à prática educativa. 33a . ed. São Paulo: Paz e Terra, 1997.

FREIRE, Paulo; SHOR, Ira. Medo e ousadia: o cotidiano do professor. Rio deJaneiro: Paz e Terra, 1986.

GERLIC, Sebastián. Coleção Índio na visão dos índios: memória. Salvador: Thydêwá, 2011.

LAZANEO, Caio de Salvi. Produção Partilhada do Conhecimento: Uma experiência com as comunidades indígenas Xavantes e Karajá. 2012. 155 f. Dissertação (Mestrado em Ciências da Comunicação da Escola de Comunicação e Arte) - Universidade de São Paulo, 2012.

MESQUITA, Alexsandro Cosmo. E o verbo se fez digital: Uma narrativa sobre cultura indígena, tecnologia e formação. 2016. 199 f. Dissertação (Mestrado em 
Tecnologias da Inteligência e Design Digital) - Pontifícia Universidade Católica de São Paulo, 2016.

PEREIRA, Eliete. Net-ativismo indígena brasileiro: notas sobre a atuação comunicativa indígena nas redes digitais. In: DI FELICE, Massimo; PEREIRA, Eliete; ROZA, Erick (orgs.). Net-ativismo: redes digitais e novas práticas de participação. Campinas: Papirus: 2017. p. 169-182.

PESCE, Lucila; BRUNO, Adriana Rocha. Educação e inclusão digital: consistências e fragilidades no empoderamento dos grupos sociais. Dossiê - In/exclusão digital e Educação. Educação (PUC RS). v. 38, n. 03, set.-dez. 2015. p. 349-357. Disponível em: http://revistaseletronicas.pucrs.br/fo/ojs/index.php/faced/article/view/21779. Acesso em 9 março de 2018.

TAVARES, Joana Brandão. Ciber-informações nativas: uma análise da circulação da informação dos cibermeios de autoria de povos indígenas residentes no território brasileiro (2005-2012). 2013. 435 f. Dissertação de Mestrado em Jornalismo - Universidade Federal, Santa Catarina, 2013.

TRIP, David. Pesquisa-ação: uma introdução metodológica. Educação e Pesquisa, São Paulo, v. 31, n.3, p. 443-466, set./dez. 2005. Disponível em: http://www. scielo.br/pdf/ep/v31n3/a09v31n3.pdf. Acesso em 20 de maio de 2017.

\section{ALEXSANDRO COSMO DE MESQUITA}

CV Lattes: http://lattes.cnpq.br/7027049700492629 ORCID: https://orcid. org/0000-0001-9427-1618

e-mail: alex.cmesquita@gmail.com telefone: (11) 98547-7594 Endereço residencial: Avenida João de Barros, 155 - AP 52A, Largo do Socorro, São Paulo - SP, CEP:04764-090.

\section{LUCILA PESCE}

CV Lattes: http://lattes.cnpq.br/4867232275873194 ORCID: http://orcid. org/0000-0002-2562-2012

e-mail: lucilapesce@gmail.com telefone: (11) 9 9940-1231 Endereço residencial: Rua Carlos Weber, 1319 apto. 162, Vila Leopoldina SP, SP, CEP: 05303-000

\section{ANA MARIA DI GRADO HESSEL}

CV Lattes: http://lattes.cnpq.br/2150241303883701 ORCID: http://orcid. org/0000-0003-4776-7754

e-mail: digrado@uol.com.br telefone: (11)9 9969-4979 Endereço residencial:

Rua Coronel Arbues, 84, Santana, São Paulo, SP, CEP: 02403-040 